\title{
next generation
}

_ Als ich die Ergotherapieschulbank gedrückt habe, lag in meinem Kurs das Durchschnittsalter bei 30 Jahren. Von unserem 16-jährigen Nesthäkchen bis zur 47-jährigen Umschülerin waren sämtliche Alters- und Lebenserfahrungsklassen vertreten. Ich habe das damals als bereichernde Mischung empfunden.

_ Heute ist die Situation anders, wie unser Artikel ab Seite 36 zeigt. Immer mehr Ergotherapieschüler sind schon mit 17 Jahren in der praktischen Ausbildung anzutreffen. Dort kämpfen sie mit einer bis dato unbekannten Größe: der therapeutischen Rolle. Gar nicht so einfach als Teenie. Ich kann mich an meinen ersten Einsatz in der praktischen Ausbildung noch gut erinnern. Ich war damals zwar „schon“ 23 Jahre alt, fühlte mich in meiner Position vor einer 10-köpfigen Klientengruppe in der Psychiatrie dennoch alles andere als gefestigt.

_ Aber man wächst ja bekanntlich mit seinen Aufgaben. So auch in meinem nächsten Einsatz in der Neurologie. Der von meinen Dozenten immer wieder gepredigte „Transfer in den Alltag“ erwies sich bei einem mir zugewiesenen Klienten als ein zähes Unterfangen. Zu Hause üben wollte er nicht, sein Leiden sollte einzig und allein ich in der wöchentlichen Behandlung „richten“. Ein klarer Fall von fehlender Motivation! Da muss man keine Ergotherapieschülerin sein, um an seine Grenzen zu stoßen. Der Artikel ab Seite 20 hätte mir damals weitergeholfen. Denn so viel sei schon mal verraten: Wer erkennt, welchem Motivationstyp sein Klient entspricht, kann ihn erfolgreich zur aktiven Mitarbeit bringen.

_ Meines Erachtens sind Dozenten und Praxisanleiter heute mehr denn je gefordert, ihre Schüler auch auf dem Weg zu reifen Persönlichkeiten zu begleiten und damit eine wichtige Investition in die neue ErgotherapieGeneration zu leisten.

_ Aber nun lade ich Sie dazu ein, ein bisschen Zeit zu investieren. Wir haben in dieser Ausgabe ergopraxis-Ostereier versteckt. Finden Sie alle und gewinnen Sie einen Buchgutschein!

Viel Spaß bei der Eiersuche und einen schönen Frühling wünscht Ihnen
ZU GEWINNEN

Kursplatz

1 Kurs „Basale Stimulation“ oder „Bewegtes Lagern“ Seite 45

Bücher

1 Buchgutschein

3-mal „Ristorante

Pronto, Pronto“

3-mal „Fallbuch Ergotherapie

in der Pädiatrie“

Seite 24

3-mal „Der ganz

normale Wahnsinn“

Seite 34

Und außerdem ...

2-mal das „Geschenkset

Kräuterkiste“

Seite 29

Im ergopraxis.Refresher

2-mal „Ergotherapie im Arbeitsfeld Neurologie"

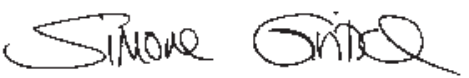

